\title{
Surface Modification of Barium Sulfate Particles
}

\author{
Jérémy Longlade, Christelle Delaite, Anne-Sophie Schuller \\ Laboratoire de Photochimie et d'Ingénierie Macromoléculaires, Université de Haute Alsace (UHA), Mulhouse Cedex, France \\ Email: anne-sophie.schuller@uha.fr
}

How to cite this paper: Longlade, J., Delaite, C. and Schuller, A.-S. (2021) Surface Modification of Barium Sulfate Particles. Materials Sciences and Applications, 12, 1-14. https://doi.org/10.4236/msa.2021.121001

Received: November 6, 2020

Accepted: January 12, 2021

Published: January 15, 2021

Copyright $\odot 2021$ by author(s) and Scientific Research Publishing Inc. This work is licensed under the Creative Commons Attribution International License (CC BY 4.0).

http://creativecommons.org/licenses/by/4.0/ (c) (i) Open Access

\begin{abstract}
In this study, surface modification of barium sulfate was investigated using several model molecules for chemical treatment: ethanesulfonic acid, butyric acid, trimethoxy(propyl) silane and phosphoric acid 2-hydroxyethyl methacrylate. Samples were characterized by FT-IR and TGA to check the capability of these model molecules to interact with $\mathrm{BaSO}_{4}$ surface. The results pointed out the presence of an organic layer around the surface after the chemical treatment even after several washings to remove all species in excess. Model molecules were grafted onto $\mathrm{BaSO}_{4}$ surface and grafted density was determined. It reveals that phosphoric acid and carboxylic acid are the best candidates for the modification of $\mathrm{BaSO}_{4}$ surface. Both can be used as anchoring groups to modify the hydrophilic balance of barium sulfate surface in order to avoid the formation of aggregates and to improve the compatibility of this filler within hydrophobic polymer matrix.
\end{abstract}

\section{Keywords}

Barium Sulfate, Surface Modification, Grafted Density

\section{Introduction}

Barium sulfate $\left(\mathrm{BaSO}_{4}\right)$ is available as barites, its naturally occurring form, or Blanc fixe which is a synthetic precipitate. Most barites are extracted from layers of sedimentary rock and used as weighting agent in oil or during natural gas drilling due to their high specific gravity [1]. Blanc fixe, is generally obtained by purification processes of barites, and has been widely used in many applications because of its whiteness, inertness, and opacity to X-rays [2] [3] [4]. It has been extensively used in industrial applications, as additives in pharmaceutical products or as filler and extenders in polymers and paints [4]-[10]. Blanc fixe is 
added in polymer formulations to reduce cost (replacement of titanium dioxide) and reinforce mechanical properties of paint films [9] [11] [12].

As the surface of $\mathrm{BaSO}_{4}$ is hydrophilic, it is very difficult to disperse these particles in a lipophilic polymer matrix, resulting in a dramatically decrease of mechanical properties of materials [13]. For this reason, and in order to improve the dispersion of the $\mathrm{BaSO}_{4}$ particles in the polymer matrix, it is essential to carry out modifications of their surface.

The objective of this study is to graft onto the surface of $\mathrm{BaSO}_{4}$ some model molecules, in order to determine the best anchoring group. Functionalization can enhance the mechanical properties of polymeric films, due to the reinforcement of filler/polymer interface. Strong bonds between the grafting agent and the filler are able to ensure an optimal stress transfer between the polymer matrix and the inorganic particles [14] [15].

In literature, different modifying agents are employed especially to control morphology of synthetic barite crystal or to modify hydrophobic balance of barium sulfate nanoparticles during the synthesis. The most significant are carboxylic acid, and organic phosphorous groups. For example, the use of ethylenediaminetetraacetic acid (EDTA) has been reported for the controlled synthesis of $\mathrm{BaSO}_{4}$ [9] [10] [16]. EDTA forms a complex with $\mathrm{Ba}^{2+}$, controlling the reactivity of $\mathrm{Ba}^{2+}$ ions during the precipitation of $\mathrm{BaSO}_{4}$. The adsorption of polyelectrolytes like polyacrylates and polysulfonates are also described [17]. In the same way, phosphonate groups are used to modulate morphology and properties of barite crystals during their synthesis [18] [19]. Studies highlight the role of phosphate in the control of particle size and modification of surface properties of $\mathrm{BaSO}_{4}$, attributed to the presence of barium alkyl phosphonate [5]. Indeed, very few studies concern the post modification of barium sulfate particles [20]. However, in the paints and polymers industry in general, the coupling or dispersing agents are introduced at the same time as the filler.

The aim of this study is to analyze the barium sulfate surface after a chemical surface treatment with different functions in an organic solvent medium, in order to highlight specific interactions between functional groups and barite surface.

\section{Materials and Methods}

\subsection{Materials}

Blanc Fixe Micro ( $\mathrm{BaSO}_{4}$, Sachtleben), Ethanesulfonic acid 95\% (186260 Aldrich), Butyric acid $\geq 99 \%$ (B103500 Aldrich), Trimethoxy(propyl) silane 97\% (662275 Aldrich), Phosphoric acid 2-hydroxyethyl methacrylate > 90\% (SR 9054, Sartomer), Toluene anhydrous 99.8\% (244511 Sigma-Aldrich), and N-Butyl Acetate (Univar) were used as received. All model molecules are presented in Figure 1.

The average particles diameter of $\mathrm{BaSO}_{4}$ is $860 \pm 22 \mathrm{~nm}$ (determined by dynamic light scattering-Malvern Mastersizer, dry process) and the specific area is equal to $2.5 \mathrm{~m}^{2} / \mathrm{g}$ (determined by BET analysis). 
<smiles>CCS(=O)(=O)O</smiles>

Ethanesulfonic acid<smiles>CCCC(=O)O</smiles>

Butyric acid

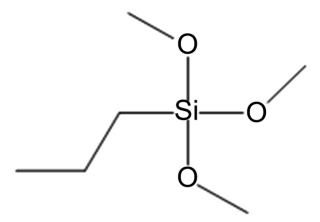

Trimethoxy(propyl) silane<smiles>[R]OP([R])(=O)O[R]</smiles>

$\mathrm{R}=$ and/or<smiles>C=C(C)C(=O)OCCC</smiles>

Phosphoric acid 2-hydroxyethyl methacrylate(SR 9054)

Figure 1. Structure of organic molecules used as models.

\subsection{Sample Preparation}

To perform the chemical surface treatment of barium sulfate particles, $10 \mathrm{~g}$ of $\mathrm{BaSO}_{4}, 4 \mathrm{~g}$ of model molecules diluted in $100 \mathrm{ml}$ of appropriate solvent (toluene for butyric acid and trimethoxy(propyl) silane, butyl acetate for phosphoric acid 2-hydroxyethyl methacrylate and ethanesulfonic acid) are mixed and heated at $80^{\circ} \mathrm{C}$ under magnetic stirring. After $1 \mathrm{~h}$, the mixture is cooled down to room temperature and then centrifuged to remove solvent. 4 cycles of washing with appropriate solvent are performed by centrifugation to remove the species in excess. The $\mathrm{BaSO}_{4}$ powder is then dried $15 \mathrm{~h}$ at $80^{\circ} \mathrm{C}$ in an oven and then pelletized by compression molding. In case of untreated $\mathrm{BaSO}_{4}, 10 \mathrm{~g}$ of $\mathrm{BaSO}_{4}$ are mixed with toluene (or butyl acetate) and heat at $80^{\circ} \mathrm{C}$ during 1 hour under magnetic stirring. Then, the mixture is cooled down to room temperature, centrifuged to remove solvent and finally dried $15 \mathrm{~h}$ at $80^{\circ} \mathrm{C}$ in an oven.

\subsection{Methods}

\subsubsection{FT-IR}

FT-IR analyses were performed using a VERTEX 70 spectrometer. All spectra were recorded from 400 to $4000 \mathrm{~cm}^{-1}$ using platinum diamond ATR. The molecules used as models and pelletized $\mathrm{BaSO}_{4}$ powders were analyzed.

\subsubsection{Thermogravimetric Analysis}

$\mathrm{BaSO}_{4}$ powders (treated and untreated) were analyzed by thermogravimetric analysis (TGA) using a Q50 TGA from TA Instruments. All samples were heated from $30^{\circ} \mathrm{C}$ to $800^{\circ} \mathrm{C}$ at $10^{\circ} \mathrm{C} /$ min under nitrogen.

\section{Results and Discussion}

In order to graft organic molecules onto the surface of barium sulfate particles, model molecules and $\mathrm{BaSO}_{4}$ powder were mixed in appropriate solvent and heat at $80^{\circ} \mathrm{C}$ during $1 \mathrm{~h}$. Model molecules were introduced in a large excess to allow a potential grafting onto the surface. Hence, several washings of powders were 
performed using appropriate solvent (solvent used for chemical treatment) to remove the excess of model molecules which are not grafted onto the surface of inorganic particles. Finally, powders were dried to remove solvent during $15 \mathrm{~h}$ at $80^{\circ} \mathrm{C}$ and analyzed by FT-IR and TGA.

\subsection{FT-IR Analyses}

FT-IR analyses were performed in order to detect organic molecules onto the surface of inorganic particles (Figure 2). Strong absorptions were observed from 600 to $1200 \mathrm{~cm}^{-1}$ corresponding to stretching bands of barium sulfate. The presence of a large band at $3400 \mathrm{~cm}^{-1}$ is attributed to the stretching vibration of absorbed water on the hydrophilic surface of particles [5] [10] [21]. Spectrum highlights the difficulty to analyze organic residue due to the strong absorption of barium sulfate. In fact, the characteristic groups of organic molecules (trialkoxysilane, phosphoric acid or sulfonic acid groups) have bands located in the same zone as those of barium sulfate. So no significant difference is observed between the spectra, except for particles treated with phosphoric acid 2-hydroxyethyl methacrylate for which barium sulfate absorption bands are largest, which is probably due to the phosphorous compounds (hydrogen bonds).

In order to identify the characteristic groups of the various organic molecules outside the barium sulphate absorption zone, zooms were carried out between 1400 and $4000 \mathrm{~cm}^{-1}$ (Figure 3 and Figure 4).

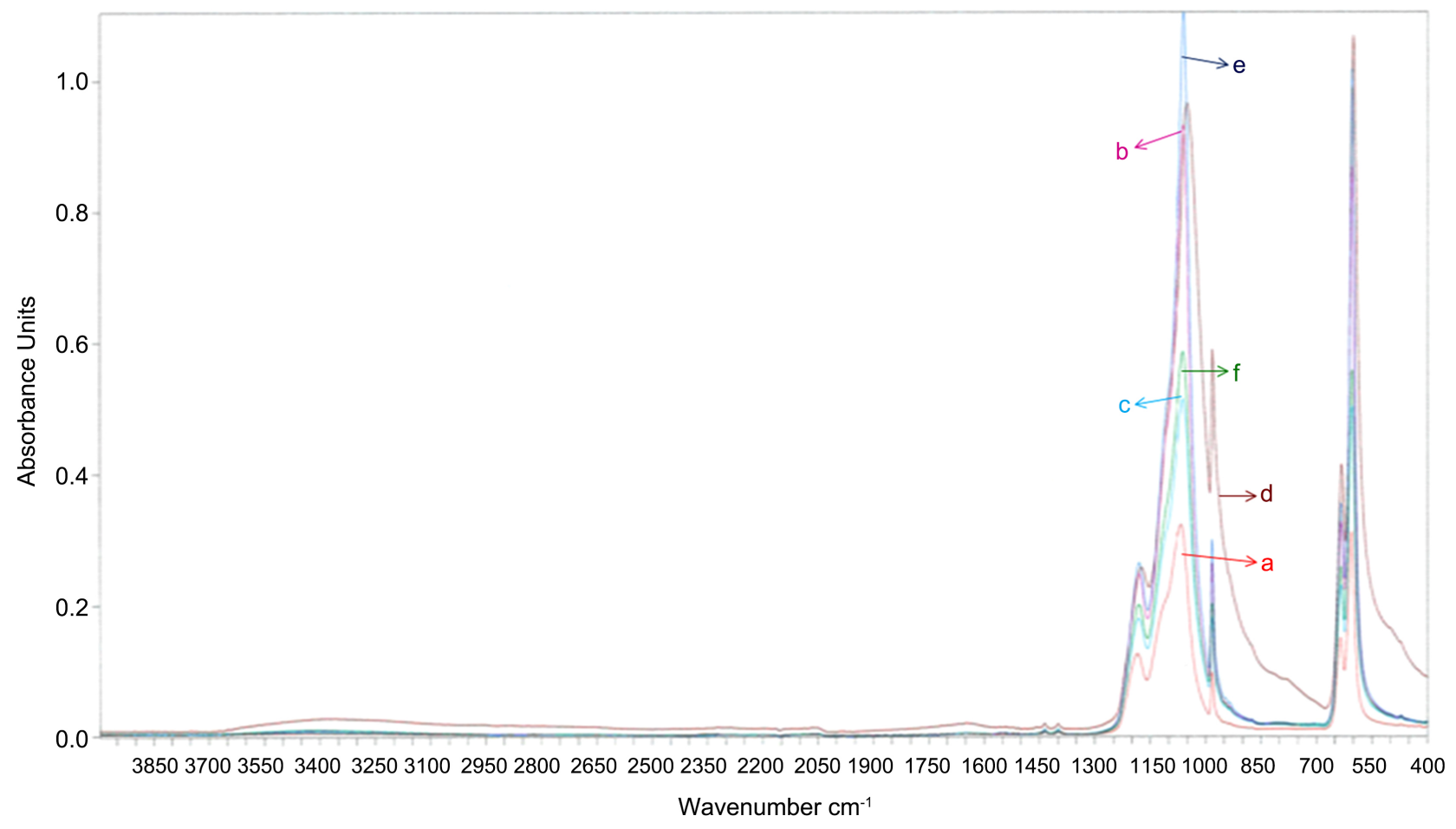

Figure 2. FT-IR comparison of modified particles and unmodified particles. Sulfate barium particles (a) Mixed in butyl acetate without model molecules, (b) Mixed in toluene without model molecules, (c) Modified with ethanesulfonic acid in butyl acetate, (d) Modified with phosphoric acid 2-hydroxyethyl methacrylate in butyl acetate, (e) Modified with butyric acid in toluene, (f) Modified with trimethoxy(propyl) silane in toluene. 


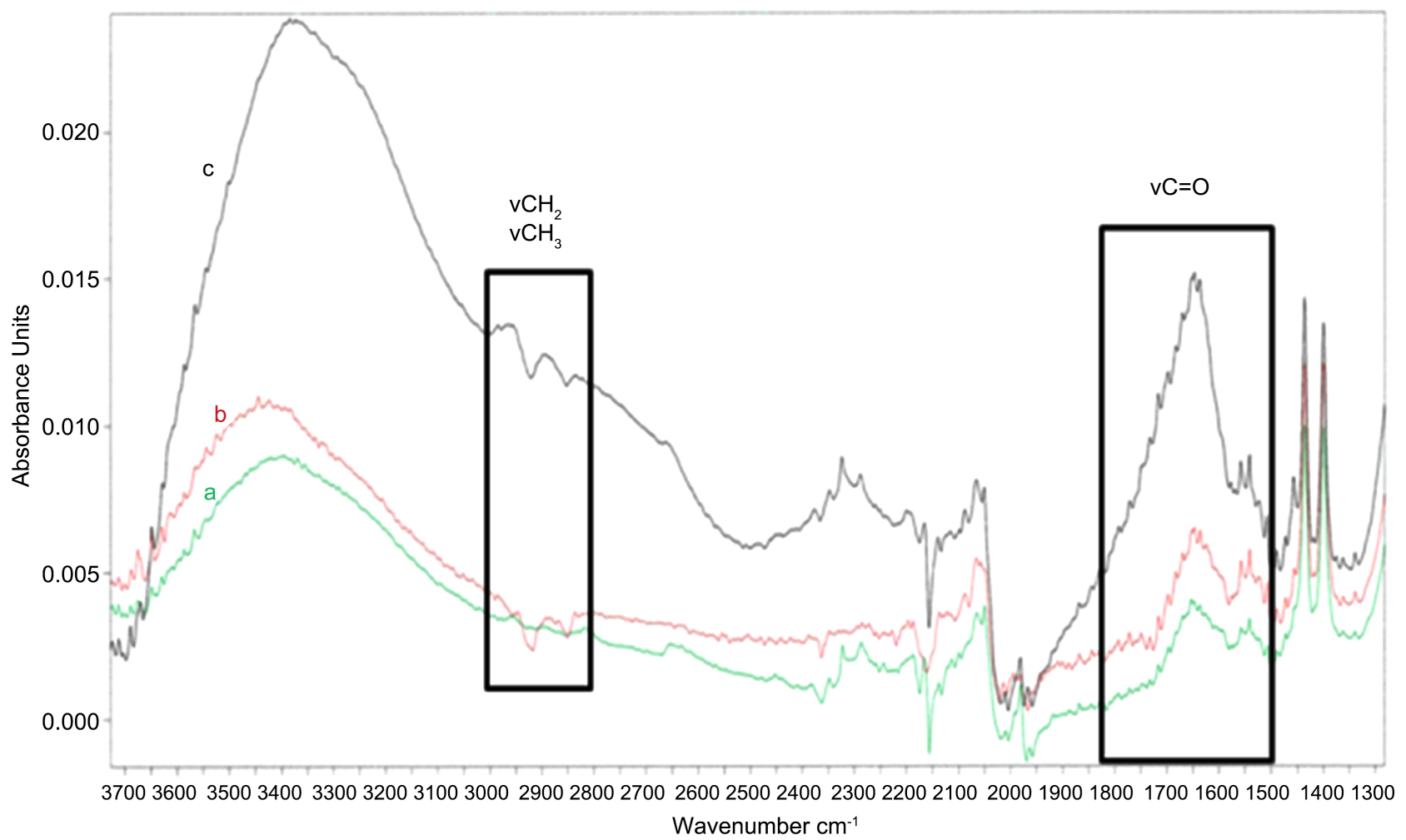

Figure 3. Zoom of FT-IR spectra: Comparison of unmodified particles (a), Modified with ethanesulfonic acid (b) and Modified with phosphoric acid 2-hydroxyethyl methacrylate (c) in butyl acetate.

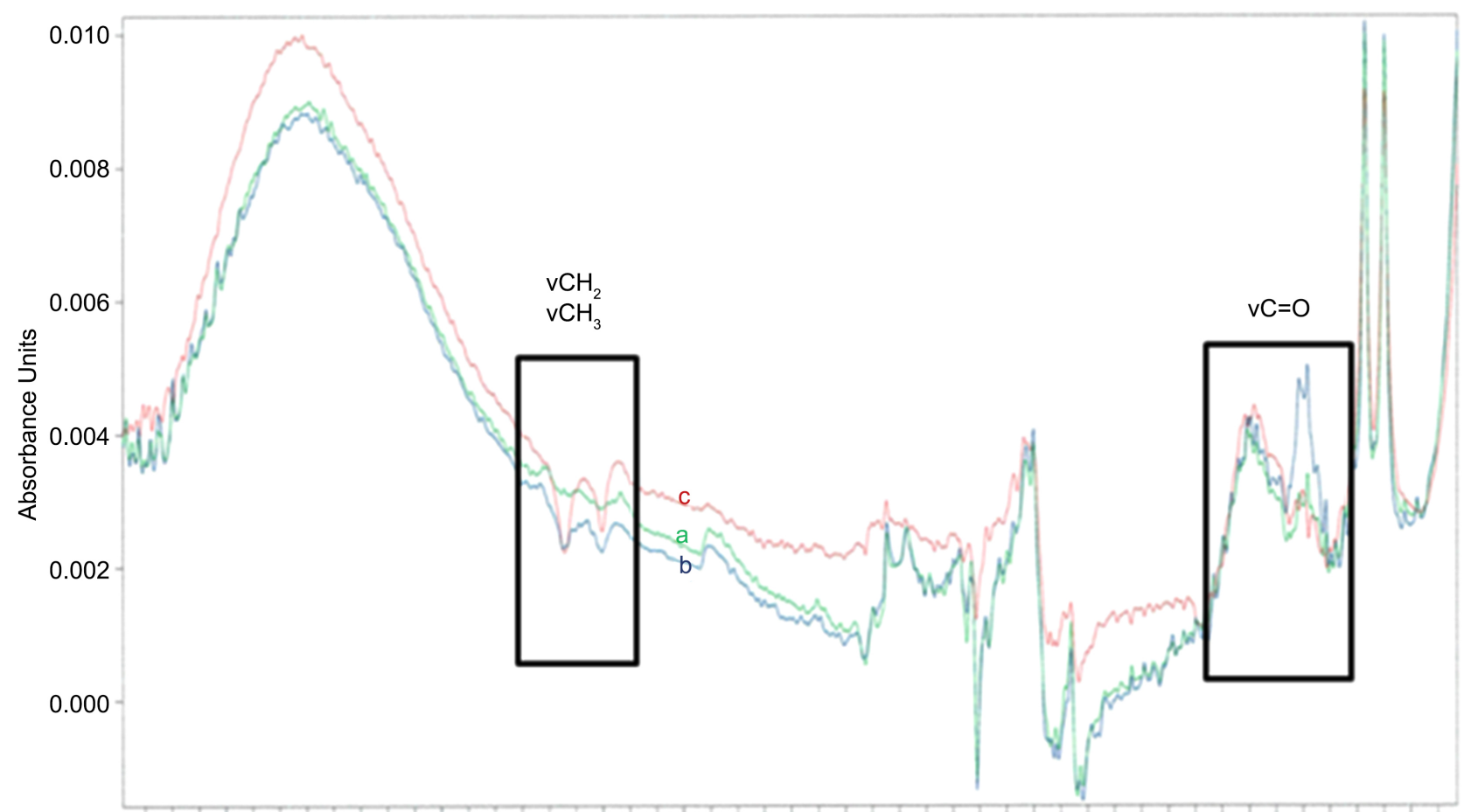

3700360035003400330032003100300029002800270026002500240023002200210020001900180017001600150014001300 Wavenumber $\mathrm{cm}^{-1}$

Figure 4. Zoom of FT-IR spectra: Comparison of unmodified particles (a), Modified with butyric acid (b) and Modified with trimethoxy(propyl) silane (c) in toluene. 
IR spectra of particles treated in butyl acetate with ethanesulfonic acid or phosphoric acid 2-hydroxyethyl methacrylate are presented in Figure 3. Analyses were focused on two areas: $2800-3000 \mathrm{~cm}^{-1}$ and $1450-1750 \mathrm{~cm}^{-1}$. The presence of absorption bands at $2900 \mathrm{~cm}^{-1}$ only for phosphoric acid compound treated particles is attributed to the vibration mode of alkyl groups ( $v \mathrm{C}-\mathrm{H})$, corresponding to aliphatic chains of phosphoric acid 2-hydroxyethyl methacrylate [21]. Thus, other band at $1650 \mathrm{~cm}^{-1}$, which is assigned to the $\mathrm{C}=\mathrm{O}$ stretching vibration mode of the ester groups of phosphoric acid 2-hydroxyethyl methacrylate, confirms the existence of phosphoric acid groups onto the surface of barium sulfate. In counterpart, no specific bands of ethanesulfonic acid are observed. To conclude, FT-IR analyses of modified particles show that only phosphoric acid group is able to interact with the $\mathrm{BaSO}_{4}$ surface.

Figure 4 presents the inorganic particles treated in toluene with butyric acid or trimethoxy(propyl) silane. As previously, the large peak at $3000 \mathrm{~cm}^{-1}$ can be attributed to the stretching vibration mode of alkyl groups for both trialkoxysilane and carboxylic acid derivates, and underlines the presence of organic groups. Thus, from 1500 to $1700 \mathrm{~cm}^{-1}$, a new peak appears for particles modified with butyric acid. It was assigned to the $\mathrm{C}=\mathrm{O}$ stretching vibration mode of carboxylic acid. The shift of this band compared to the $\mathrm{C}=\mathrm{O}$ of free butyric acid $\left(1700 \mathrm{~cm}^{-1}\right.$ observed by FT-IR of raw material) indicates that the complex between $\mathrm{COO}^{-}$ and $\mathrm{Ba}^{2+}$ ions has been formed [10].

The presence of silane at the surface of the $\mathrm{BaSO}_{4}$ particles, however, cannot be observed by IR.

\subsection{Thermogravimetric Analyses (TGA)}

Thermogravimetric analyses were performed on all samples to quantify the presence of residual grafted molecules for treated $\mathrm{BaSO}_{4}$ compared to an untreated one.

Figure 5 shows the TGA curves obtained for untreated $\mathrm{BaSO}_{4}$ and treated $\mathrm{BaSO}_{4}$. The curves (a) and (b) correspond to thermogravimetric analyses of untreated $\mathrm{BaSO}_{4}$ mixed with butyl acetate and toluene respectively. The curves are very close (less than $10 \%$ of standard deviation), suggesting that powders contain no solvent residues. Until $200^{\circ} \mathrm{C}$, the weight loss corresponds to physical desorption of water at the barium sulfate surface. Beyond $200^{\circ} \mathrm{C}$ (from $200^{\circ} \mathrm{C}$ to $550^{\circ} \mathrm{C}$ ), the weight loss is due to the elimination of chemisorbed water and to decomposition of barium hydroxides [5] [22].

The curves (c), (d), (e) and (f) refer to thermogravimetric analyses of $\mathrm{BaSO}_{4}$ treated with ethanesulfonic acid, phosphoric acid 2-hydroxyethyl methacrylate, butyric acid and trimethoxy(propyl) silane respectively. Except for ethanesulfonic acid, for which the curve is similar to the reference, all curves present a significant weight loss compared to the raw $\mathrm{BaSO}_{4}$. In fact, a more important weight loss than for untreated $\mathrm{BaSO}_{4}$ is observed until nearly $300^{\circ} \mathrm{C}$. These weight losses relate to the adsorption of organic molecules at the surface of particles. 


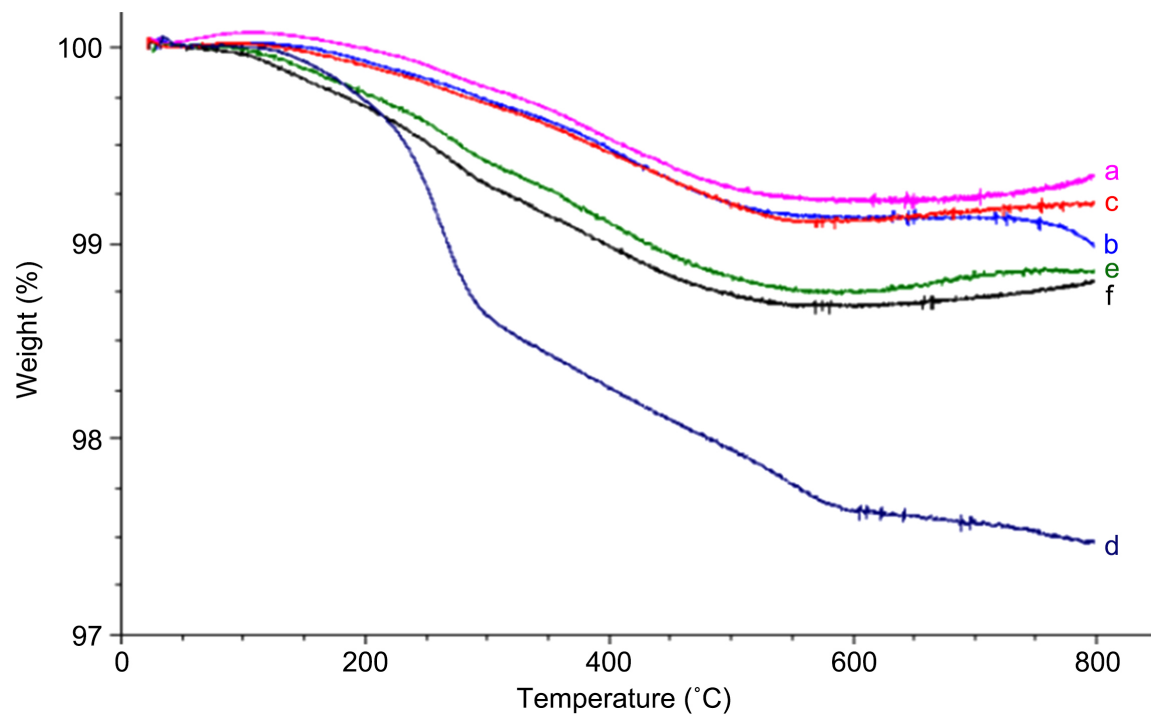

Figure 5. TGA of untreated particles in butyl acetate (a) or toluene (b), treated particles with ethanesulfonic acid (c), phosphoric acid 2-hydroxyethyl methacrylate (d), butyric acid (e) and trimethoxy(propyl) silane (f).

However, the weight losses are very low (less than 2\%), because of the weak specific area of $\mathrm{BaSO}_{4}\left(2.5 \mathrm{~m}^{2} / \mathrm{g}\right)$. That means that the grafted density of molecules onto $\mathrm{BaSO}_{4}$ surface is very low.

In spite of the low weight losses, the grafted densities of organic molecules were calculated.

Firstly, if the weight losses of untreated particles are only due to water desorption because of decomposition of barium hydroxides, their weight loss contribution on treated particles can be determined (\%ref $=0.809 \%$ and $0.879 \%$ for untreated $\mathrm{BaSO}_{4}$ in butyl acetate and toluene respectively).

So, the weight losses due to the degradation of organic molecules grafted onto the surface $(\Delta \mathrm{mGM})$ can be deduced from Equation (1).

$$
\Delta \mathrm{m}_{\mathrm{GM}}=\Delta \mathrm{m}-\%_{\text {ref }} * \mathrm{~m}
$$

where, $\Delta \mathrm{m}_{\mathrm{GM}}$ is the weight loss of the treated filler after the degradation of organic molecules used as models, $\Delta \mathrm{m}$ the total weight loss of treated particles determined by TGA, $\%_{\text {ref }}$ the percentage weight loss due to adsorbed water and hydroxide groups condensation, and $\mathrm{m}$ the mass of treated particles used as sample for thermogravimetric analysis.

From $\Delta \mathrm{m}_{\mathrm{GM}}$, the grafting density (molecules $/ \mathrm{nm}^{2}$ ) of organic molecules can be calculated using Equation (2).

$$
\text { Grafting density }=\frac{\Delta \mathrm{m}_{\mathrm{GM}} * \mathrm{~N}_{\mathrm{A}} * 10^{18}}{\mathrm{~S}_{\mathrm{p}} * \mathrm{~m} * \mathrm{M}_{\mathrm{TGA}}}
$$

where, $\Delta \mathrm{m}$ GM is the weight loss of the treated filler due to the degradation of organic molecule, $\mathrm{N}_{\mathrm{A}}$ the Avogadro constant, $\mathrm{Sp}$ the specific surface area of particles $\left(2.5 \mathrm{~m}^{2} / \mathrm{g}\right), \mathrm{m}$ the mass of particles used as sample for thermogravimetric analysis and MTGA the molar mass of degraded organic molecule. 
Some hypotheses were taken into account for the molar mass values MTGA. For ethanesulfonic acid and butyric acid, all molecules were degraded as gases: carbon dioxide, carbon monoxide, alkenes for butyric acid and sulfur dioxide and alkenes for ethanesulfonic acid [23]. So the molar masses of raw materials were used.

However, in case of trialkoxysilane and phosphoric acid compounds, only the organic parts of initial molecules are thermally degraded. The silicon and the phosphorus remained at the $\mathrm{BaSO}_{4}$ surface in form of silica [SiOx] and phosphorus oxide [POx] residues respectively. Water adsorbed on particles and thermal activation lead to the hydrolysis and condensation of these species (Figure 6) [23] [24] [25].

In order to evaluate the stability of trimethoxy(propyl) silane during the surface modification process, chemical treatment was renewed in benzene-d6 (instead of anhydrous toluene) at $65^{\circ} \mathrm{C}$ during $1 \mathrm{~h} 30$. The hydrolysis of trialkoxysilane was followed by ${ }^{1} \mathrm{H} \mathrm{NMR}$, using the evolution of the proton peaks corresponding to both the methyl groups attached to the silane $\left(-\mathrm{Si}-\left(\mathrm{OCH}_{3}\right)_{3}\right)$ and those released during the hydrolysis $\left(\mathrm{CH}_{3}-\mathrm{OH}\right)$, appearing at 3.44 and $3.07 \mathrm{ppm}$, respectively (Figure 7) [26] [27]. Analysis of supernatant revealed the presence of about $2 \%$ molar of methanol already observed before the treatment. Thus, no evolution of methyl groups attached to the silane was highlighted. Therefore, this trialkoxysilane is stable in anhydrous solution. However, the weight loss observed by TGA for $\mathrm{BaSO}_{4}$ treated with alkoxysilane suggests that the condensation of trialkoxysilane onto $\mathrm{BaSO}_{4}$ surface in anhydrous solvents can take place. In fact, it was reported that the traces of water physisorbed onto oxide surface can hydrolyze alkoxysilanes. Then, the hydrolyzed species can react with the hydroxyl groups present on the surface of the oxide via a hydrogen bond or a covalent bond. Finally, the growth of the organosilane layer occurs by condensation of hydrolyzed silanes [28] [29].

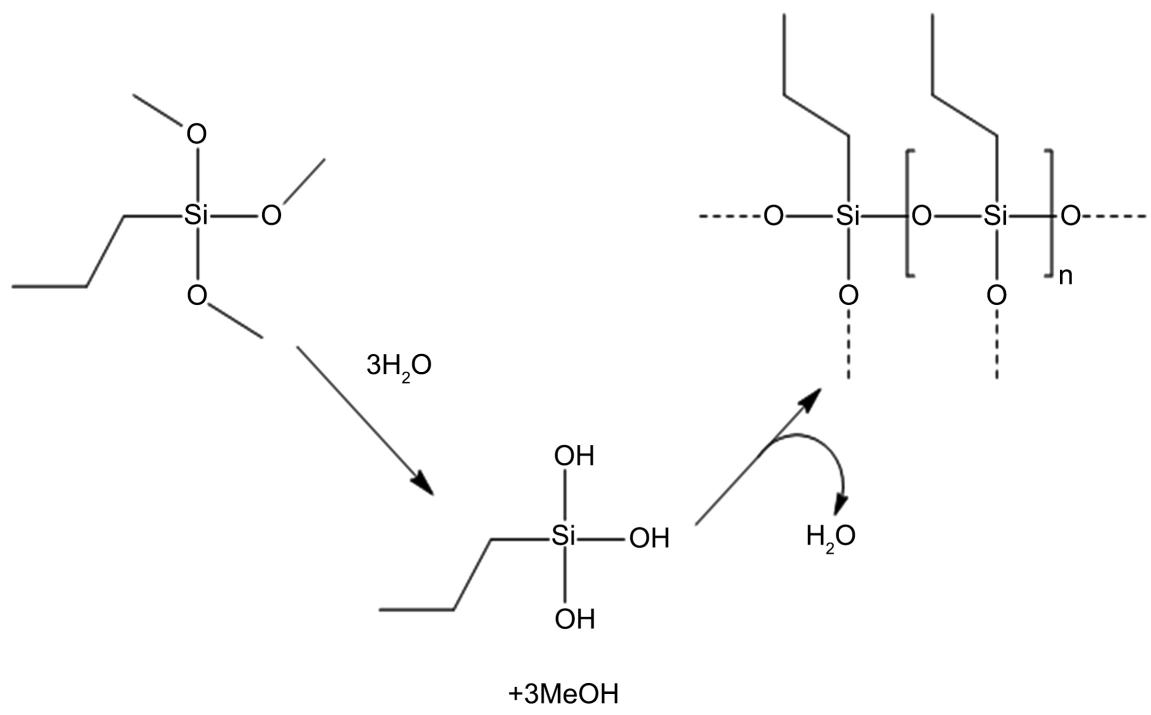

Figure 6. Example of hydrolysis and condensation of trialkoxysilane. 


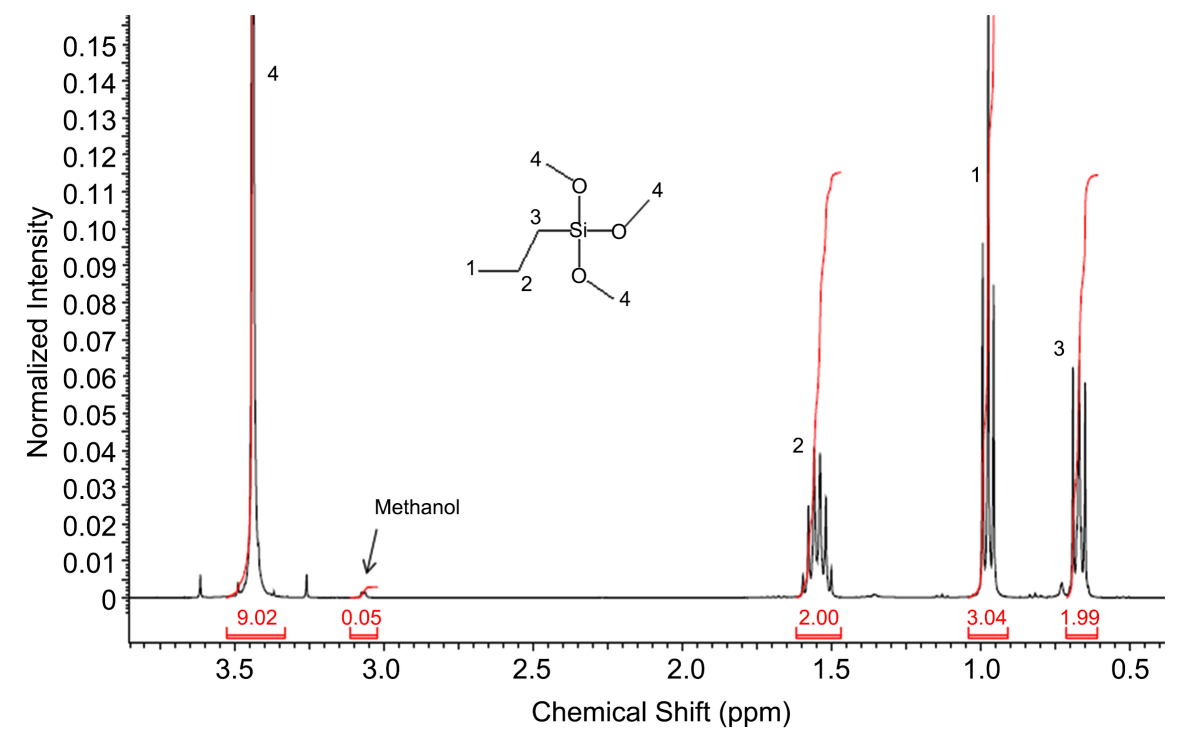

Figure 7. ${ }^{1} \mathrm{H}$ NMR of trimethoxy(propyl) silane after $1 \mathrm{~h}$ at $65^{\circ} \mathrm{C}$ in benzene-d6 in presence of barium sulfate.

It is likely that the alkoxysilane was only partially hydrolyzed during the treatment. It was assumed that only one of methyl groups attached to the silane was hydrolyzed. Methanol produced by the hydrolysis of trialkoxysilane was removed by the cycles of washing before TGA analysis. The weight losses observed were probably due to the alkane gases issued from the degradation of the carbon chain (considered as propane) and the methanol issued from the degradation of methyl groups which were not hydrolyzed during chemical treatment (considered as methanol). The molar mass MTGA of the organic part degraded from trimethoxy(propyl) silane is given by Equation (3).

$$
\mathrm{M} \text { silane TGA }=\text { MPropane }+2 * \text { MMethanol }=108.18 \mathrm{~g} / \mathrm{mol}
$$

For phosphoric acid 2-hydroxyethyl methacrylate, only organic part of molecules, i.e. 2-hydroxyethyl methacrylate (HEMA) is degraded.

There are three possibilities according to the supplier data. $\mathrm{R} 1=\mathrm{R} 2=\mathrm{RA}$ named $\mathrm{AA}, \mathrm{R} 1=\mathrm{RA} / \mathrm{R} 2=\mathrm{RB}$ named $\mathrm{AB}$ and $\mathrm{R} 1=\mathrm{R} 2=\mathrm{RB}$ named $\mathrm{BB}$ (Figure 8).

For this reason, grafting densities taking into account the three cases $\mathrm{AA}, \mathrm{AB}$ and $\mathrm{BB}$ described previously have to be calculated. The molar masses of degraded organic molecules due to these three species are summarized in Table 1.

${ }^{31} \mathrm{P}$ NMR spectroscopy was performed in order to determine the relative percentage of different species AA, AB and BB (Figure 9). The ${ }^{31} \mathrm{P}$ NMR spectrum reveals that phosphoric acid 2-hydroxyethyl methacrylate contains two major compounds as orthophosphate, monoester $(\mathrm{AB})$ and diester $(\mathrm{BB})$ of phosphoric acid 2-hydroxyethyl methacrylate [30] [31]. The triester (AA), orthophosphate and polyphosphates are in minority. These minor species were neglected for the determination of grafting density. The relative molar ratio of $\mathrm{AB}$ and $\mathrm{BB}$ were calculated using peak integration (Equation (4)). The results show a molar content of $56.7 \%$ of $\mathrm{BB}$ and $43.3 \%$ of $\mathrm{AB}$. 


$$
\% \mathrm{~mol}_{\mathrm{BB}}=\frac{(\mathrm{BB}) \text { peak integration }}{(\mathrm{BB})+(\mathrm{AB}) \text { peak integration }} * 100
$$

The molar mass Mphosphoric acid TGA of degraded phosphoric acid 2-hydroxyethyl methacrylate calculated is $186.44 \mathrm{~g} / \mathrm{mol}$, using Equation (5).

$$
\mathrm{M}_{\text {phosphoric acid TGA }}=\left(2-\% \mathrm{~mol}_{\mathrm{BB}}\right) * \mathrm{M}_{\mathrm{HEMA}}
$$

where $\%$ mol $\mathrm{BB}$ is the relative molar percentage of phosphoric acid monoester compared to total of monoester and diester and MHEMA the molar mass of 2-hydroxyethyl methacrylate $(130.14 \mathrm{~g} / \mathrm{mol})$.

The molar mass values MTGA used and the calculated grafting densities for all organic compounds are summarized in Table 2. The grafting density for ethanesulfonic acid is very low, in accordance with IR analysis. The conclusion is that sulfonic acid is not a good anchoring group to establish strong interactions with barium sulfate. The grafting density of trialkoxysilane, carboxylic acid and phosphoric acid derivates are more important. Hypotheses used for the calculated grafted density of alkoxysilane exclude the formation of multilayer. However, it is possible that the hydrolysis of methoxy groups is upper than $25 \%$, and leads to the formation of multilayers. Despite this, the calculated value is considered to be representative of the actual grafting density.<smiles>[R20][P+]([R])([R])OCCOC(=O)C(=C)C</smiles><smiles>[R][CH-]CCOC(=O)C(=C)C</smiles>

$$
\mathrm{R}_{\mathrm{B}}={ }^{*}-\mathrm{H}
$$

Figure 8. Structure of phosphoric acid 2-hydroxyethyl methacrylate.

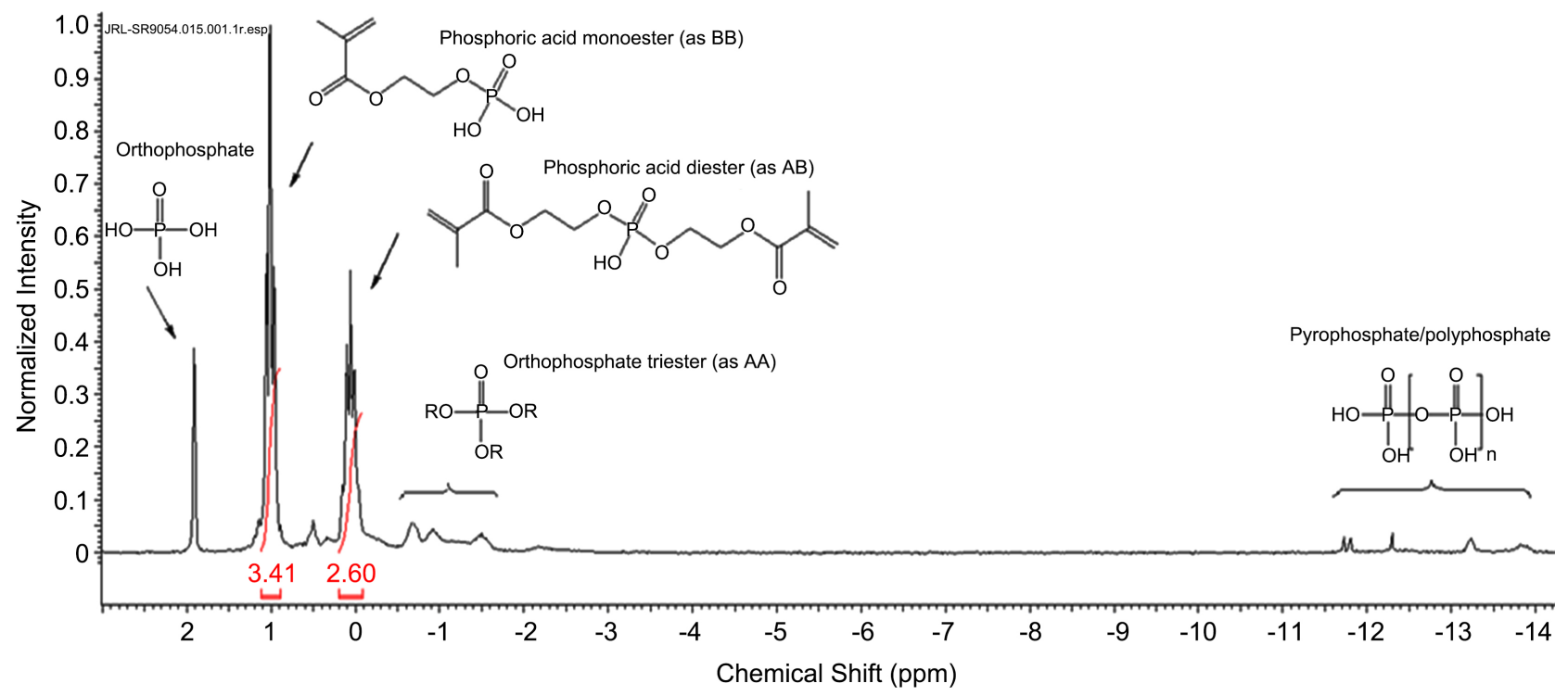

Figure 9. ${ }^{31} \mathrm{P} \mathrm{NMR}$ of phosphoric acid 2-hydroxyethyl methacrylate in $\mathrm{CDCl}_{3}$. 
Table 1. Molar masses of degraded organic molecules in function of species present in phosphoric acid 2-hydroxyethyl methacrylate.

\begin{tabular}{cc}
\hline Species & Molar masses of degraded molecules \\
\hline $\mathrm{AA}$ & $\mathrm{M}_{\mathrm{AA}}=3 \mathrm{M}_{\mathrm{HEMA}}=390.42 \mathrm{~g} / \mathrm{mol}$ \\
$\mathrm{AB}$ & $\mathrm{M}_{\mathrm{AB}}=2 \mathrm{M}_{\mathrm{HEMA}}=260.28 \mathrm{~g} / \mathrm{mol}$ \\
$\mathrm{BB}$ & $\mathrm{M}_{\mathrm{BB}}=\mathrm{M}_{\mathrm{HEMA}}=130.14 \mathrm{~g} / \mathrm{mol}$ \\
\hline
\end{tabular}

Table 2. Grafting densities of organic model molecules onto barium sulfate surface.

\begin{tabular}{cccc}
\hline & $\begin{array}{c}\Delta \mathrm{m}_{\mathrm{GM}} / \mathrm{m} \\
(\%)\end{array}$ & $\begin{array}{c}\mathrm{M}_{\mathrm{TGA}} \\
(\mathrm{g} / \mathrm{mol})\end{array}$ & $\begin{array}{c}\text { Grafting density } \\
\left(\text { molecules } / \mathrm{nm}^{2}\right)\end{array}$ \\
\hline Ethanesulfonic acid & $0.08^{(\mathrm{a})}$ & 110.1 & 1.7 \\
Phosphoric acid 2-hydroxyethyl methacrylate & $1.57^{(\mathrm{a})}$ & 186.5 & 20.3 \\
Trimethoxy(propyl) silane & $0.45^{(\mathrm{b})}$ & 108.2 & 9.9 \\
Butyric acid & $0.38^{(\mathrm{b})}$ & 88.1 & 10.5 \\
\hline
\end{tabular}

${ }^{(a)}$ Calculated using Equation (1) with untreated $\mathrm{BaSO}_{4}$ in butyl acetate as reference: $\%$ ref $=0.809 \%$ (obtained by TGA); ${ }^{(b)}$ Calculated using Equation (1) with untreated $\mathrm{BaSO}_{4}$ in toluene as reference: \%ref $=0.879 \%$ (obtained by TGA); ${ }^{(\mathrm{c})}$ According to Equation (2).

The grafted densities for butyric acid and phosphoric acid 2-hydroxyethyl methacrylate are the highest. They are upper than 10 molecules $/ \mathrm{nm}^{2}$. Carboxylic and phosphoric acids are therefore good candidates as anchoring groups on the surface of barium sulfate. Thus, phosphoric acid groups seem to be more appropriate than carboxylic acid groups according to calculated grafting density.

To conclude, TGA made it possible to distinguish the effectiveness of several functions in anchoring to the surface of barium sulfate. It underlines that phosphoric acid and carboxylic acid groups are good anchoring groups for barium sulfate.

\section{Conclusion}

The aim of this study was to analyze the barium sulfate surface after a chemical surface treatment with organic model molecules in order to define the best anchoring groups for $\mathrm{BaSO}_{4}$ surface modification. FT-IR analyses and TGA have pointed out the presence of a residual organic layer after the chemical treatment of barium sulfate for all models compounds, even after several washings performed to remove species in excess, excepted for ethanesulfonic acid. This indicates that the organic layer is strongly absorbed on the $\mathrm{BaSO}_{4}$ particles. A classification of the groups capable of anchoring to the surface of the $\mathrm{BaSO}_{4}$ particles was determined based on the grafting densities calculated by TGA: phosphoric acid $>$ carboxylic acid $>$ trialkoxysilane $>$ sulfonic acid.

\section{Acknowledgements}

The authors want to thanks Mäder company for its financial support. 


\section{Conflicts of Interest}

The authors declare no conflicts of interest regarding the publication of this paper.

\section{References}

[1] Yap, J., Leong, Y.K. and Liu, J. (2011) Structural Recovery Behaviour of BariteLoaded Bentonite Drilling Muds. Journal of Petroleum Science and Engineering, 78, 552-558. https://doi.org/10.1016/j.petrol.2011.06.010

[2] Romero-Ibarra, I.C., Bonilla-Blancas, E., Sanchez-Solis, A. and Manero, O. (2012)

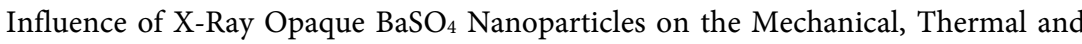
Rheological Properties of Polyoxymethylene Nanocomposites. Journal of Polymer Engineering, 32, 319-326. https://doi.org/10.1515/polyeng-2011-0135

[3] Yang, J.-N., Xu, Y.-X, Nie, S.-B, Cheng, G.-J, Tao, Y.-L and Zhu, J.-B. (2018) Morphological Structure, Impact Toughness, Thermal Property and Kinetic Analysis on the Cold Crystallization of Poly (Lactic Acid) Bio-Composites Toughened by Precipitated Barium Sulfate. Polymer Degradation and Stability, 158, 176-189. https://doi.org/10.1016/j.polymdegradstab.2018.11.008

[4] Yang, J., Wang, C., Shao, K., Ding, G., Tao, Y. and Zhu, J. (2015) Morphologies, Mechanical Properties and Thermal Stability of Poly (Lactic Acid) Toughened by Precipitated Barium Sulfate. Russian Journal of Physical Chemistry, 89, 2092-2096. https://doi.org/10.1134/S0036024415110242

[5] Bala, H., Fu, W., Guo, Y., Zhao, J., Jiang, Y., Ding, X., Yu, K., Li, M. and Wang, Z. (2006) In Situ Preparation and Surface Modification of Barium Sulfate Nanoparticles. Colloids and Surfaces A: Physicochemical and Engineering Aspects, 274, 71-76. https://doi.org/10.1016/j.colsurfa.2005.08.050

[6] El-Ghaffar M.A. A, Abdelwahab, N.A., Fekry Amany, M., Sanad, M.A., Sabaa, M.W. and Soliman, S.M.A. (2020) Polyester-Epoxy Resin/Conducting Polymer/Barium Sulfate Hybrid Composite as a Smart Eco-Friendly Anti-Corrosive Powder Coating. Progress in Organic Coatings, 144, 105664. https://doi.org/10.1016/j.porgcoat.2020.105664

[7] Kopeć, M., Rossenaar, B.D., van Leerdam, K., Davies, A.N., Lyon, S.B., Visser, P. and Gibbon, S.R. (2020) Chromate Ion Transport in Epoxy Films: Influence of Ba$\mathrm{SO}_{4}$ Particles. Progress in Organic Coatings, 147, 105739. https://doi.org/10.1016/j.porgcoat.2020.105739

[8] Wang, F., Xu, G., Zhang, Z. and Xin, X. (2005) Morphology Control of Barium Sulfate by PEO-PPO-PEO as Crystal Growth Modifier. Colloids and Surfaces A: Physicochemical and Engineering Aspects, 259, 151-154. https://doi.org/10.1016/j.colsurfa.2005.02.025

[9] Romero-Ibarra, I.C., Bonilla-Blancas, E., Sánchez-Solís, A. and Manero, O. (2012) Influence of the Morphology of Barium Sulfate Nanofibers and Nanospheres on the Physical Properties of Polyurethane Nanocomposites. European Polymer Journal, 48, 670-676. https://doi.org/10.1016/j.eurpolymj.2012.01.001

[10] Zhang, M., Zhang, B., Li, X., Yin, Z. and Guo, X. (2011) Synthesis and Surface Properties of Submicron Barium Sulfate Particles. Applied Surface Science, 258, 24-29. https://doi.org/10.1016/j.apsusc.2011.07.137

[11] Koleske, J.V. (1995) Paint and Coating Testing Manual, Chapter 24.

[12] Talbert, R. (2007) Paint Technology Handbook. CRC Press, Boca Raton, Chapter 2, 220. https://doi.org/10.1201/9781420017786 
[13] Bowditch, M.R. and Stannard, K.J. (1984) The Interaction of Water with a BarytesFilled Polyurethane. International Journal of Adhesion and Adhesives, 4, 175-178. https://doi.org/10.1016/0143-7496(84)90027-7

[14] Schuller, A.S., Delaite, C. and Farge, H. (2011) Effect of a Formulation Named "Giral” on Mechanical Properties of a Composite Based on Silica and Unsaturated Polyester Resin. Polymer Bulletin, 66, 77-94. https://doi.org/10.1007/s00289-010-0319-5

[15] Mallakpour, S. and Madani, M. (2015) A Review of Current Coupling Agents for Modification of Metal Oxide Nanoparticles. Progress in Organic Coatings, 86, 194 207. https://doi.org/10.1016/j.porgcoat.2015.05.023

[16] Zhao, Y.H. and Liu, J.R. (2006) Effect of EDTA and Phosphate on Particle Size during Precipitation of Nanosized $\mathrm{BaSO}_{4}$ Particles. Chemistry Letters, 35, 1040-1041. https://doi.org/10.1246/cl.2006.1040

[17] Wright, J.A., Harrop, R., Williams, P.A., Pass, G. and Robb, I.D. (1987) Exchange and Competitive Adsorption of Polyelectrolytes on Barium Sulphate. Colloids and Surfaces, 24, 249-258. https://doi.org/10.1016/0166-6622(87)80354-2

[18] Black, S.N., Bromley, L.A., Cottier, D., Davey, R.J., Dobbs, B. and Rout, J.E. (1991) Interactions at the Organic/Inorganic Interface: Binding Motifs for Phosphonates at the Surface of Barite Crystals. Journal of the Chemical Society, Faraday Transactions, 87, 3409-3414. https://doi.org/10.1039/ft9918703409

[19] Lee, S.S., Kim, J., Park, M., Lim, S. and Choe, C.R. (2001) Transesterification Reaction of the $\mathrm{BaSO}_{4}$-Filled PBT/Poly(Ethylene Terephthalate) Blend. Journal of Polymer Science Part B: Polymer Physics, 39, 2589-2597. https://doi.org/10.1002/polb.10011

[20] Li, L.L., Hang, J.Z. and Shi, L.Y. (2009) Surface Modification of Barite Nanoparticles Using Stearate. Journal of Shanghai University(English Edition), 13, 296-300. https://doi.org/10.1007/s11741-009-0409-1

[21] Socrates, G. (2001) Infrared and Raman Characteristic Group Frequencies: Tables and Charts. 3rd Edition, Wiley, Hoboken.

[22] Duval, C. (1963) Inorganic Thermogravimetric Analysis. 2nd Edition, Elsevier Publishing Company, Amsterdam.

[23] Jiang, D.D., Yao, Q., McKinney, M.A. and Wilkie, C.A. (1999) TGA/FTIR Studies on the Thermal Degradation of Some Polymeric Sulfonic and Phosphonic Acids and Their Sodium Salts. Polymer Degradation and Stability, 63, 423-434. https://doi.org/10.1016/S0141-3910(98)00123-2

[24] McElwee, J., Helmy, R. and Fadeev, A.Y. (2005) Thermal Stability of Organic Monolayers Chemically Grafted to Minerals. Journal of Colloid and Interface Science, 285, 551-556. https://doi.org/10.1016/j.jcis.2004.12.006

[25] Cochez, M., Ferriol, M., Weber, J.V., Chaudron, P., Oget, N. and Mieloszynski, J.L. (2000) Thermal Degradation of Methyl Methacrylate Polymers Functionalized by Phosphorus-Containing Molecules I. TGA/FT \pm IR Experiments on Polymers with the Monomeric Formula $\mathrm{CH}_{2} \mathrm{C}\left(\mathrm{CH}_{3}\right) \mathrm{C}(\mathrm{O}) \mathrm{OCHRP}(\mathrm{O})\left(\mathrm{OC}_{2} \mathrm{H}_{5}\right)_{2}\left(\mathrm{R}=\mathrm{H},\left(\mathrm{CH}_{2}\right)_{4} \mathrm{CH}_{3}\right.$, $\mathrm{C}_{6} \mathrm{H}_{5} \mathrm{Br}, \mathrm{C}_{10} \mathrm{H}_{7}$. Polymer Degradation and Stability, 70, 455-462. https://doi.org/10.1016/S0141-3910(00)00141-5

[26] Brochier Salon, M.-C., Abdelmouleh, M., Boufi, S., Belgacem, M.N. and Gandini, A. (2005) Silane Adsorption onto Cellulose Fibers: Hydrolysis and Condensation Reactions. Journal of Colloid and Interface Science, 289, 249-261. https://doi.org/10.1016/j.jcis.2005.03.070

[27] Brochier Salon, M.-C., Bayle, P.-A., Abdelmouleh, M., Boufi, S. and Belgacem, M.N. 
(2008) Kinetics of Hydrolysis and Self-Condensation Reactions of Silanes by NMR Spectroscopy. Colloids and Surfaces A: Physicochemical and Engineering Aspects, 312, 83-91. https://doi.org/10.1016/j.colsurfa.2007.06.028

[28] Flesh, C., Joubert, M., Bourgeat-Lami, E., Mornet, S., Duguet, E., Delaite, C. and Dumas, P. (2005) Organosilane-Modified Maghemite Nanoparticles and Their Use as Co-Initiator in the Ring-Opening Polymerization of $\varepsilon$-Caprolactone. Colloids and Surfaces A: Physicochemical and Engineering Aspects, 262, 150-157.

https://doi.org/10.1016/j.colsurfa.2005.04.039

[29] Azzopardi, M.J. and Arribart, H. (1994) In Situ FTIR Study of the Formation of an Organosilane Layer at the Silica/Solution Interface. The Journal of Adhesion, 46, 103-115. https://doi.org/10.1080/00218469408026653

[30] Cade-Menun, B.J. (2005) Characterizing Phosphorus in Environmental and Agricultural Samples by ${ }^{31} \mathrm{P}$ Nuclear Magnetic Resonance Spectroscopy. Talanta, 66, 359371. https://doi.org/10.1016/j.talanta.2004.12.024

[31] Plass, J., Emeis, D. and Blümich, B. (2001) ${ }^{31}$ P Nuclear Magnetic Resonance Studies on Alkyl Phosphate Emulsifiers in Cosmetic Oil-in-Water Emulsions. Journal of Surfactants and Detergents, 4, 379-384. https://doi.org/10.1007/s11743-001-0191-3 